Full length article

\title{
Proteomic and metabolomic responses in D-shape larval mussels Mytilus galloprovincialis exposed to cadmium and arsenic
}

\author{
Huifeng $\mathrm{Wu}^{\mathrm{a},{ }^{*} \text {, Lanlan } \mathrm{Xu}}{ }^{\mathrm{a}, \mathrm{b}}$, Chenglong Ji ${ }^{\mathrm{a}}$, Deliang $\mathrm{Yu}^{\mathrm{a}, \mathrm{b}}$ \\ ${ }^{a}$ Key Laboratory of Coastal Zone Environmental Processes, Yantai Institute of Coastal Zone Research (YIC), Chinese Academy of Sciences (CAS), Shandong \\ Provincial Key Laboratory of Coastal Zone Environmental Processes, YICCAS, Yantai 264003, PR China \\ ${ }^{\mathrm{b}}$ University of Chinese Academy of Sciences, Beijing 100049, PR China
}

\section{A R T I C L E I N F O}

\section{Article history:}

Received 14 August 2016

Received in revised form

28 September 2016

Accepted 30 September 2016

Available online 1 October 2016

\section{Keywords:}

Mytilus galloprovincialis

Cadmium

Arsenic

Biological effects

Proteomics

Metabolomics

\begin{abstract}
A B S T R A C T
Cadmium (Cd) and arsenic (As) are the main metal/metalloid contaminants in the coastal environments of the Bohai Sea, China. In this work, a combined proteomic and metabolomic approach was applied to investigate the biological effects of $\mathrm{Cd}$ and $\mathrm{As}(\mathrm{V})$ in the early life stage (D-shape larvae) of mussel Mytilus galloprovincialis. Results indicated that $\mathrm{Cd}$ was a potential immune toxicant to D-shape larval mussel because of the numerous proteomic responses related to immune system. Additionally, Cd induced oxidative stress, cellular injury and disturbance in nucleic acid metabolism in D-shape larval mussels. However, only two identified proteins were significantly altered in As (V)-treated group, suggesting that $\mathrm{D}$-shape larval mussel was less sensitive to $\mathrm{As}(\mathrm{V})$ than to $\mathrm{Cd}$ at protein level. These two proteins in response to As $(\mathrm{V})$ suggested that $A s(\mathrm{~V})$ influenced anti-oxidative system and cell proliferation in Dshape larval mussels. Metabolic responses indicated that $\mathrm{Cd}$ and $\mathrm{As}(\mathrm{V})$ induced disturbances in osmotic regulation and energy metabolism in D-shape larval mussels via different metabolic pathways. In addition, Cd reduced lipid metabolism as well. This work demonstrated that a combination of proteomics and metabolomics could provide an insightful view in the biological effects of pollutants in mussel $M$. galloprovincialis at an early life stage.
\end{abstract}

(c) 2016 Published by Elsevier Ltd.

\section{Introduction}

As it is known, there are numerous metal (e.g., zinc, gold) mining and smelting factories along the Bohai coast, which has led to severe metal pollution in the Bohai marine and coastal environments. Mu et al. (2009) found that Cd and As were the dominant metal pollutants in the sediments from the Laizhou Bay [1]. In the mussels collected from the Bohai Sea in China, a survey reported that the mussels from some of the sampling sites were polluted by $\mathrm{Cd}$ and As with average concentrations at $\sim 2$ and $5 \mu \mathrm{g} / \mathrm{L}$, respectively [2]. In our recent study, the $\mathrm{Cd}$ and As pollution have been confirmed by the high accumulations of $\mathrm{Cd}$ and As in marine shrimp Crangon affinis collected from the Yellow River Estuary and Laizhou Bay along the Bohai coast, respectively [3]. Although Cd is relatively rare in marine environment, the concentration of $\mathrm{Cd}$ has reached $50 \mu \mathrm{g} / \mathrm{L}$ in some heavily polluted estuaries or harbors and ports [4]. In open ocean seawater, the concentration of total arsenic

\footnotetext{
* Corresponding author.

E-mail address: hfwu@yic.ac.cn (H. Wu).
}

is usually around $1 \mu \mathrm{g} / \mathrm{L}$ and As (V) is the dominant form of inorganic arsenic [5].

Both $\mathrm{Cd}$ and As are known carcinogens and environmental toxicants inducing multiple toxicities in animals. Cd may inactivate many metabolic enzymes by competing for the catalytic sites with other metals [6,7]. In addition, both $\mathrm{Cd}$ and As can induce oxidative stress in animals by producing excessive reactive oxygen species [8]. Since Cd and As have become severe metal/metalloid contaminants in the Bohai coast, it is necessary to characterize the biological effects of $\mathrm{Cd}$ and As in marine animals.

As two main -omic approaches in system biology, proteomics and metabolomics, have been well-established and successfully applied in marine biology $[9,10]$. Since proteomics and metabolomics can directly characterize the minor metabolite and protein responses, these two - omic techniques and their combination have represented their practicability to elucidate the biological effects and mechanisms of pollutants in environmental bioindicators. Especially, a combination of proteomics and metabolomics could validate and complement one another, when testing the biological effects of environmental pollutants [11,12].

Marine mussels are widely used as bioindicators in 
environmental monitoring and assessment programs because of their sessile filter, feeding lifestyle and high accumulation for organic and inorganic pollutants in the marine environment [13]. Usually, the adult mussels are applied in either ecotoxicology or environmental monitoring programs. Due to the immature defense system, however, the early life stages of animals are more sensitive than adults, which may present differential responsive profiles to environmental pollutants [14]. To our knowledge, the responses of early life stages of mussels under Cd and As (V) stresses were not fully characterized. Consequently, it is necessary to elucidate the biological effects and responsive mechanisms in the early life stage of mussel exposed to the environmentally relevant concentration of $\mathrm{Cd}$ and $\mathrm{As}(\mathrm{V})$. In this work, we planned to use the early life stage, Dshape larval mussel M. galloprovincialis, as the experimental animal to elucidate the biological effects of $\mathrm{Cd}$ and As at an environmentally relevant concentration $(5 \mu \mathrm{g} / \mathrm{L})$. Both two-dimensional gel electrophoresis (2-DE)-based proteomics and proton nuclear magnetic resonance ( ${ }^{1} \mathrm{H}$ NMR)-based metabolomics were conducted on the D-shape larval mussel samples to elucidate the biological effects of Cd and As (V) in the early life stage (D-shape larvae) of mussel M. galloprovincialis.

\section{Materials and methods}

\subsection{Larvae breeding and experimental design}

Adult mussels M. galloprovincialis reached sexual maturity were collected in April 2015 from a less disturbed site (Yantai, China). All mussels were transported to the laboratory and acclimatized in aerated natural seawater (salinity $31 \mathrm{ps} \mu$ ) at $21{ }^{\circ} \mathrm{C}$ for 7 days. After acclimatization, these mussels were kept in the air in dark place for $2 \mathrm{~h}$. Then each mussel was put into a beaker containing warmer seawater $\left(24{ }^{\circ} \mathrm{C}\right)$. After $2 \mathrm{~h}$, the majority of mussels came to ovulation and spermiation. The 500 mesh sieve screen was used to filter impurities. Then the sperms and eggs were quickly collected to fertilize. All the fertilized eggs were then transferred into normal filtered seawater $(50 \mathrm{~L})$ in a bucket. Continuous aeration was conducted during incubation. After approximately $48 \mathrm{~h}$, the majority of fertilized eggs developed into D-shape larvae (Fig. 1). Then the Dshape larval mussels were divided into three groups (control, Cd (as $\mathrm{CdCl}_{2}$ ) and $\mathrm{As}(\mathrm{V})$ (as $\mathrm{Na}_{3} \mathrm{AsO}_{4}$ ) exposures) each containing 8 buckets $(50 \mathrm{~L})$ with a density of $\sim 25 \mathrm{D}$-shape larval per milliliter. The environmentally relevant concentration $(5 \mu \mathrm{g} / \mathrm{L})$ of $\mathrm{Cd}$ and As was used for the exposures of D-shape larval mussels M. galloprovincialis. During the acclimatization and exposure

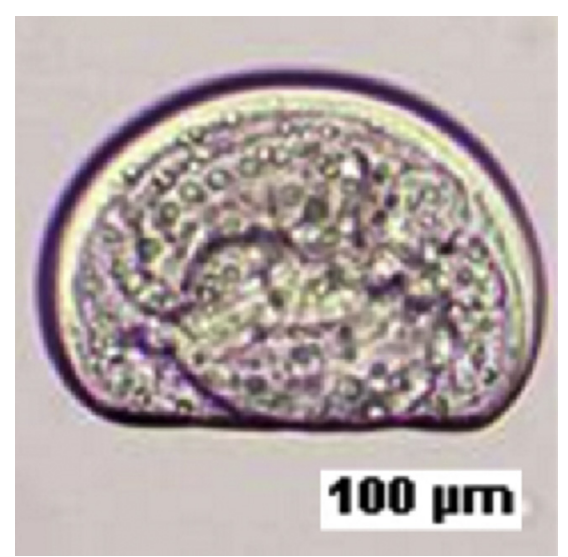

Fig. 1. A representative image of a D-shape larval mussel $M$. galloprovincialis from control group. periods, all the D-shape larvae were kept under a photoperiod of $12 \mathrm{~h}$ light and $12 \mathrm{~h}$ dark, and fed with the Chlorella vulgaris daily. In control and treatment groups, all the D-shape larval mussels were not significantly different in morality and morphology. After exposure for $48 \mathrm{~h}$, all the larvae $\left(\sim 1.0-1.3 \times 10^{6}\right.$ individuals) from each bucket were immediately filtered out by 500 mesh sieve screen and collected into two larvae samples for proteomic and metabolomic analysis, respectively. These D-shape larval mussel samples were quickly snap-frozen in liquid nitrogen and stored at $-80{ }^{\circ} \mathrm{C}$.

\subsection{Metabolite and protein extraction}

Polar metabolites in D-shape larval mussels ( $n=8$ for each treatment) were extracted by the extraction protocol with some modifications [15]. All the D-shape larval mussel samples (ca. $100 \mathrm{mg}$ wet weight) were homogenized and extracted in $4 \mathrm{~mL} / \mathrm{g}$ of methanol, $5.25 \mathrm{~mL} / \mathrm{g}$ of water and $2 \mathrm{~mL} / \mathrm{g}$ of chloroform. The methanol/water layer with polar metabolites was transferred to a glass vial and then dried in a centrifugal concentrator. The extracts of soft tissue were then re-suspended in $600 \mu \mathrm{L}$ of phosphate buffer ( $100 \mathrm{mM} \mathrm{Na}_{2} \mathrm{HPO}_{4}$ and $\mathrm{NaH}_{2} \mathrm{PO}_{4}$, including $0.5 \mathrm{mM} \mathrm{TSP}, \mathrm{pH} 7.0$ ) in $\mathrm{D}_{2} \mathrm{O}$. The mixture was vortexed and then centrifuged at $3000 \mathrm{~g}$ for $5 \mathrm{~min}$ at $4{ }^{\circ} \mathrm{C}$. The supernatant substance $(550 \mu \mathrm{L})$ was then pipetted into a $5 \mathrm{~mm}$ NMR tube prior to NMR analysis.

Total protein extraction was performed based on previous studies with some modifications [16,17]. Briefly, each D-shape larval mussel samples was homogenized quickly on ice with $1 \mathrm{~mL}$ of TRIzol reagent and centrifuged at $12000 \mathrm{~g}$ for $5 \mathrm{~min}$ at $4{ }^{\circ} \mathrm{C}$. The supernatant was added with $200 \mu \mathrm{L}$ of chloroform before shaking vigorously for $3 \mathrm{~min}$ and precipitating for $3 \mathrm{~min}$, then the mixture was centrifuged at $12000 \mathrm{~g}$ for $15 \mathrm{~min}$ at $4{ }^{\circ} \mathrm{C}$, and its upper aqueous layer was discarded. A volume of $300 \mu \mathrm{L}$ of absolute ethyl alcohol was added and the mixture was allowed to stand for $3 \mathrm{~min}$ at room temperature before being centrifuged at $2000 \mathrm{~g}$ for $5 \mathrm{~min}$ at $4{ }^{\circ} \mathrm{C}$. The phenol/ethanol supernatant was precipitated for $30 \mathrm{~min}$ at room temperature by the addition of $750 \mu \mathrm{L}$ of isopropanol prior to centrifugation at $14000 \mathrm{~g}$ for $10 \mathrm{~min}$ at $4{ }^{\circ} \mathrm{C}$. Pellets obtained were washed with $1 \mathrm{~mL}$ of ethanol (v/v 95\%) and centrifuged at $14000 \mathrm{~g}$ for $10 \mathrm{~min}$ at $4{ }^{\circ} \mathrm{C}$. This procedure was repeated twice. The pellets were solubilized in the lysis buffer ( $7 \mathrm{M}$ urea; $2 \mathrm{M}$ thiourea; $4 \% \mathrm{~m} / \mathrm{V}$ CHAPS; $65 \mathrm{mM}$ DTT and 0.2\%W/V Bio-lyte buffer) and then incubated for $3 \mathrm{~h}$ at room temperature. The homogenate was centrifuged at $15000 \mathrm{~g}$ for $10 \mathrm{~min}$ and the supernatant was applied to electrophoresis. The total concentrations of proteins were determined by Protein Assay Kit of TianGen.

\section{3. ${ }^{1}$ H NMR spectroscopy}

Metabolite extracts of D-shape larval mussel samples were analyzed on a Bruker AV 500 NMR spectrometer performed at $500.18 \mathrm{MHz}$ (at $25^{\circ} \mathrm{C}$ ) as described previously [18]. All ${ }^{1} \mathrm{H}$ NMR spectra were phased, baseline-corrected, and calibrated (TSP at $0.0 \mathrm{ppm}$ ) manually using TopSpin (version 2.1, Bruker).

\subsection{Spectral pre-processing and multivariate analysis}

All one dimensional ${ }^{1} \mathrm{H}$ NMR spectra were converted to a data matrix using the custom-written ProMetab software in Matlab version 7.0 (The MathsWorks, Natick, MA) [18]. Each spectrum was segmented into bins with a width of $0.005 \mathrm{ppm}$ between 0.2 and $10.0 \mathrm{ppm}$. The bins of residual $\mathrm{H}_{2} \mathrm{O}$ between 4.70 and $5.20 \mathrm{ppm}$ were excluded from all the NMR spectra. The total spectral area of the remaining bins was normalized to unity to facilitate the comparison between the spectra. All the NMR spectra were generalized 
$\log$ transformed (glog) with a transformation parameter $\lambda=2.0 \times 10^{-9}$ to stabilize the variance across the spectral bins and to increase the weightings of the less intense peaks [18]. As described in details in our previous work, data were mean-centered before multivariate analysis [18]. Furthermore, the supervised multivariate data analysis methods, partial least squares discriminant analysis (PLS-DA) and orthogonal projection to latent structure with discriminant analysis (OPLS-DA), were sequentially carried out to uncover and extract the statistically significant metabolite variations related to $\mathrm{Cd}$ and $\mathrm{As}(\mathrm{V})$ exposures, as described previously. Metabolites were assigned following the tabulated chemical shifts and by using the software, Chenomx (Evaluation Version, Chenomx Inc., Edmonton, Alberta, Canada) [18].

\subsection{Two-dimensional gel electrophoresis, image acquisition and data analysis}

For the first dimension (IEF), $130 \mu \mathrm{g}$ of protein was loaded onto IPG strips with a linear pH gradient from 4 to 7 (Immobiline Drystrip TM $24 \mathrm{~cm}$, GE Healthcare, USA) The isoelectric focusing gel solution (7 M urea, $2 \mathrm{M}$ thiourea, 4\% $\mathrm{m} / \mathrm{v}$ CHAPS, $65 \mathrm{mM}$ DTT, $0.001 \% \mathrm{~m} / \mathrm{v}$ bromophenol blue and $0.2 \% \mathrm{~W} / \mathrm{V}$ Bio-lyte buffer). IEF was conducted at $20^{\circ} \mathrm{C}$ with an Ettan IPGphor3 system for a total of $85858 \mathrm{Vh}$ (active rehydration was carried out at $30 \mathrm{~V}$ for $12 \mathrm{~h}$, followed by $100 \mathrm{~V}$ for $5 \mathrm{~h}, 500 \mathrm{~V}$ for $1 \mathrm{~h}, 1000 \mathrm{~V}$ for $1 \mathrm{~h}$, and a linear increase of voltage to $8000 \mathrm{~V}$ for $11 \mathrm{~h}$ and stand by $500 \mathrm{~V}$ for the second dimension).

After the first dimension, all the strips were placed in equilibration buffer (0.05 M Tris-HCl, pH 8.8; $6 \mathrm{M}$ urea; 30\% glycerol; $2 \%$ $(\mathrm{w} / \mathrm{v})$ SDS; containing $1 \%(\mathrm{w} / \mathrm{v})$ DTT) and were slowly shaken for $15 \mathrm{~min}$. The strips were then incubated for another $15 \mathrm{~min}$ in the equilibration buffer with $2.5 \%(\mathrm{w} / \mathrm{v})$ iodoacetamide without DTT. The second dimension was conducted on $12.5 \%$ SDS-PAGE gels using the Ettan DALTsix system. After electrophoresis, the gels were silver stained by following the method of Mortz and Gharahdaghi $[19,20]$. Images were captured by ImageScanner III and spots were quantitatively analyzed using ImageMaster 2D Platinum 7.0. For all the matched spots, only protein spots with significant changes of at least 2.0 folds, and deemed significant by Student's $t$-test at a level of $95 \%$ were accepted as differentially expressed proteins.

\subsection{In gel digestion and MS analysis}

In gel digestion was performed according to Katayama et al. [21]. After being completely dried, the D-shape larval mussel samples were re-suspended with $5 \mu \mathrm{L}$ of $0.1 \%$ TFA followed by mixing in $1: 1$ ratio with a saturated solution of $\alpha$-cyano-4-hydroxy-trans-cinnamic acid in 50\% acetonitrile [22]. One microliter of mixture was analyzed by an ABI 4800 MALDI-TOF/TOF Plus mass spectrometer (Applied Biosystems, Foster City, USA), data were acquired in a positive MS reflector using a CalMix5 standard to calibrate the instrument (ABI4800 Calibration Mixture). Both the MS and MS/MS data were integrated and processed using the GPS Explorer V3.6 software (Applied Biosystems, USA) with default parameters. Proteins were successfully identified based on $95 \%$ or higher confidence interval of their scores in the MASCOT V2.4 search engine (Matrix Science Ltd., London, U.K.). The following parameters were used in the search: NCBInr Metazoa (Animals) (2861494 sequences) database; trypsin as the digestion enzyme; one missed cleavage site; partial modifications of cysteine carbamidomethylation and methionine oxidization; no fixed modifications; 0.15 Da for precursor ion tolerance and 0.25 Da for fragment ion tolerance. Individual ions scores $>40$ indicate identity or extensive homology $(P<0.05)$.

\section{Results and discussion}

\subsection{Proteomic responses in D-shape larval mussels exposed to $C d$ and As (V)}

Proteomic responses related to $\mathrm{Cd}$ and $\mathrm{As}(\mathrm{V})$ exposures were determined by 2-DE-based proteomics in D-shape larval mussels, respectively (Fig. 2). Approximately, 1000 protein spots were resolved in the 2-DE gels from the D-shape larval mussel samples. A total of 17 spots resolved in 2-DE gels were differentially expressed ( $>2$ folds, $P<0.05$ ) in $\mathrm{Cd}$ and As $(\mathrm{V})$ treatments. Fig. 2 shows the
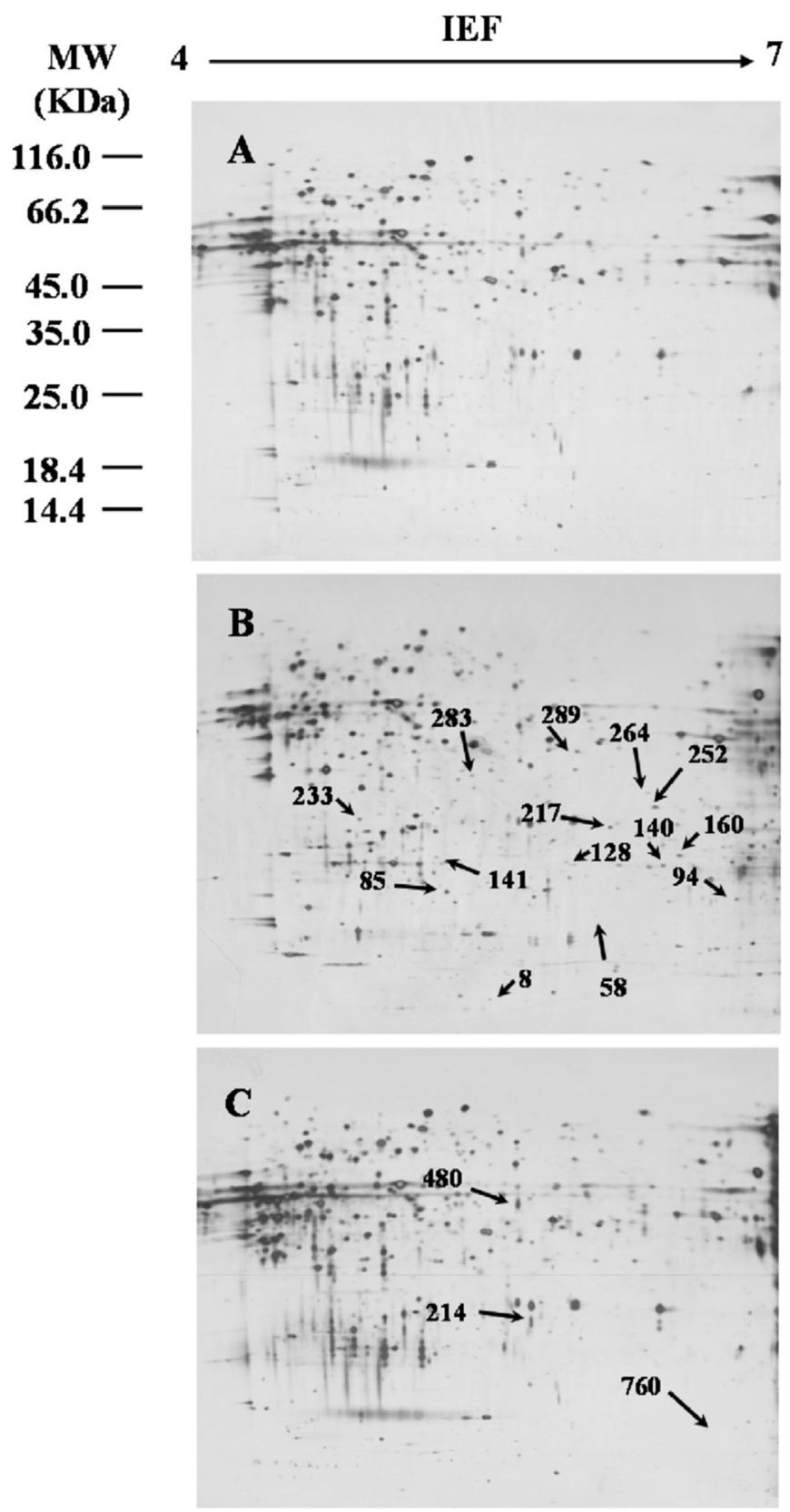

Fig. 2. Representative 2-D gels of proteins extracted from D-shape larval mussels Mytilus galloprovincialis. First dimension was performed using $130 \mu \mathrm{g}$ of total soluble proteins on linear gradient IPG strips with $\mathrm{pH} 4-7$. In the second dimension, $12.5 \%$ SDS-PAGE gels were used and proteins were visualized using silver staining. (A) control group, (B) Cd- and (C) As (V)-exposed group. Arrows show protein spots that changed significantly from inorganic As-exposed group compared to the control group. 
differential protein spots in D-shape larval mussels exposed to Cd and As (V). All the differentially expressed proteins in all three biological replicates of silver-stained gels were analyzed by MALDITOF/TOF mass spectrometry and successfully identified. The information of these proteins is summarized in Table 1.

In Cd-exposed D-shape mussel samples, a total of 14 significantly differential spots were discovered, including 12 up-regulated and 2 down-regulated. These proteins were related to stress and defense (heat shock cognate 70, DnaJ-like protein, manganese superoxide dismutase and NADH dehydrogenase), protein homeostasis and proteolysis (peptidylprolyl isomerase protein, endoplasmic reticulum protein ERp 29 and four proteasome subunits), energy (malate dehydrogenase), skeleton (dynein light chain 1 ), nucleic acid metabolism (inorganic pyrophosphatase) and cell growth and development (deoxyribonucleoside 5'-monophosphate $\mathrm{N}$-glycosidase).

Interestingly, only 3 differentially expressed proteins (2 upregulated and 1 down-regulated) were observed in As (V)exposed D-shape larval mussel samples, which might suggest that D-shape larval mussel was less sensitive to As (V) than to Cd with the environmentally relevant concentration $(5 \mu \mathrm{g} / \mathrm{L})$ at protein level. These altered proteins were basically involved in stress and defense (S-adenosylhomocysteine hydrolase) and cell growth and development (Ring box protein). One hypothetical protein was also found in As (V)-exposed D-shape larval mussel group.

As a stress protein in heat shock protein 70 family, heat shock cognate 70 is involved in immune system. It usually functions as a molecular chaperon and exerts important roles in folding of newly synthesized polypeptides, membrane translocation and degradation of misfolded proteins [23]. The DnaJ proteins, also known as heat shock protein 40 , are proteins acting as co-chaperones to the molecular chaperone, heat shock protein 70 [24]. Endoplasmic reticulum protein ERp29 is a ubiquitously expressed endoplasmic reticulum stress-inducible protein that executes protective action by binding to denatured or aggregated cellular proteins thereby facilitating their refolding [25]. Proteasomes play a critical role in ubiquitin-mediated protein degradation through the ubiquitin-proteasome pathway and are involved in cell proliferation, apoptosis and stress responses [26]. He et al. found that the transcription of proteasome in hemocytes was up-regulated in Penaeus japonicus after microbial challenge [27]. Additionally, the up-regulated proteasome was also observed in bacteria-challenged mussel M. galloprovincialis [28]. Therefore proteasomes may function as an essential component in immune system in marine invertebrates. Interestingly, four proteasome subunits were highly significantly up-regulated in Cd-treated D-shape larval mussels. Therefore, the down-regulated heat shock cognate 70, up-regulated DnaJ-like protein, endoplasmic reticulum protein ERp29 and four proteasome subunits suggested that $\mathrm{Cd}$ exposure induced severe immune stress in D-shape larval mussels due to the immature immune system at this early life stage.

Manganese superoxide dismutase plays an important role in regulating cellular redox homeostasis by catalyzing the dismutation of superoxide into oxygen and hydrogen peroxide [29]. As a flavoprotein, NADH dehydrogenase processes iron-sulfur centers and is involved in production of reactive oxygen species in mitochondria [30]. Peptidylprolyl isomerase $\mathrm{A}$ is a known protein recognized as the marker of apoptosis that is also related to oxidative stress [31]. Therefore, the significant up-regulation of manganese superoxide dismutase, NADH dehydrogenase and peptidylprolyl isomerase $A$ indicated the clear oxidative stress and consequent apoptosis induced by $\mathrm{Cd}$ in D-shape larval mussels. Malate dehydrogenase is a key metabolic enzyme in Krebs cycle that is related to energy metabolism. The up-regulated malate dehydrogenase implied the disturbance in energy metabolism induced by $\mathrm{Cd}$ in D-shape larval mussels. Moreover, malate dehydrogenase can also provide NADH for redox reaction. The upregulation of malate dehydrogenase was therefore consistent with the up-regulation of NADH dehydrogenase, which is related to oxidative stress induced by Cd treatment in D-shape larval mussels. Dynein light chain 1 is an $8-\mathrm{kDa}$ component of the cytoplasmic dynein complex that is a minus-end-directed microtubule-based motor [32]. The up-regulated dynein light chain meant the cellular injury induced by Cd in D-shape larval mussels.

Table 1

List of protein spots that differentially expressed in D-shape larval mussels Mytilus galloprovincialis exposed to Cd and As (V).

\begin{tabular}{|c|c|c|c|c|c|c|c|c|c|}
\hline Spot ID ${ }^{c}$ & Category and name & Species & gi number ${ }^{d}$ & $\mathrm{MW} / \mathrm{kDa}$ & PI & Protein score $\mathrm{e}^{\mathrm{e}}$ & $S C^{f}$ & $\mathrm{PN}^{\mathrm{g}}$ & Fold change $^{h}$ \\
\hline \multicolumn{10}{|c|}{ Stress and defense } \\
\hline 8 & Heat shock cognate 70 & Mytilus galloprovincialis & 76780612 & 71.508 & 5.29 & 1098 & $25 \%$ & 8 & $-2.16^{\mathrm{a}}$ \\
\hline 58 & DnaJ-like protein subfamily B member 11 & Crassostrea gigas & 405965494 & 154.005 & 5.05 & 276 & $3 \%$ & 3 & $2.80^{\mathrm{a}}$ \\
\hline 252 & mitochondrial Manganese superoxide dismutase & Mytilus galloprovincialis & 402122769 & 25.412 & 6.44 & 380 & $17 \%$ & 2 & $4.89^{\mathrm{a}}$ \\
\hline 233 & NADH dehydrogenase & Crassostrea ariakensis & 405968356 & 18.778 & 5.06 & 94 & $16 \%$ & 2 & $2.20^{\mathrm{a}}$ \\
\hline 760 & S-adenosylhomocysteine hydrolase & Crassostrea ariakensis & 253769244 & 48.182 & 5.97 & 62 & $2 \%$ & 2 & $-2.24^{\mathrm{b}}$ \\
\hline \multicolumn{10}{|c|}{ Protein homeostasis and proteolysis } \\
\hline 264 & Peptidylprolyl isomerase protein, partial & Crassostrea gigas & 163637061 & 14.731 & 5.29 & 58 & $6 \%$ & 2 & $2.71^{\mathrm{a}}$ \\
\hline 128 & Endoplasmic reticulum protein ERp29 & Crassostrea ariakensis & 405975720 & 28.444 & 5.19 & 51 & $6 \%$ & 3 & $3.12^{\mathrm{a}}$ \\
\hline 140 & Proteasome subunit alpha type- 4 & Crassostrea ariakensis & 405964515 & 21.464 & 5.69 & 178 & $18 \%$ & 3 & $7.51^{\mathrm{a}}$ \\
\hline 141 & Proteasome subunit beta type-3 & Crassostrea gigas & 405971643 & 18.44 & 4.85 & 181 & $19 \%$ & 2 & $2.66^{\mathrm{a}}$ \\
\hline 160 & Proteasome subunit alpha type- 6 & Crassostrea ariakensis & 405975869 & 25.429 & 7.57 & 153 & $10 \%$ & 2 & $6.85^{\mathrm{a}}$ \\
\hline 217 & Proteasome subunit alpha type- 2 & Crassostrea ariakensis & 405964525 & 26.405 & 5.52 & 330 & $24 \%$ & 4 & $10.55^{\mathrm{a}}$ \\
\hline \multicolumn{10}{|c|}{ 20 - } \\
\hline 94 & Malate dehydrogenase & Crassostrea ariakensis & 253769246 & 36.368 & 8.2 & 105 & $3 \%$ & 2 & $2.51^{\mathrm{a}}$ \\
\hline \multicolumn{10}{|c|}{ Skeleton } \\
\hline 289 & Dynein light chain 1 , axonemal, partial & Crassostrea gigas & 405970124 & 21.189 & 5.53 & 61 & $15 \%$ & 2 & $2.32^{\mathrm{a}}$ \\
\hline \multicolumn{10}{|c|}{ Nucleic acid metabolism } \\
\hline 85 & Inorganic pyrophosphatase & Crassostrea gigas & 405962800 & 48.936 & 5.75 & 47 & $2 \%$ & 1 & $2.30^{\mathrm{a}}$ \\
\hline \multicolumn{10}{|c|}{ Cell growth and development } \\
\hline 283 & Deoxyribonucleoside 5'-monophosphate $\mathrm{N}$-glycosidase & Crassostrea gigas & 405951747 & 15.878 & 5.18 & 40 & $5 \%$ & 1 & $-2.72^{\mathrm{a}}$ \\
\hline 480 & Ring box protein, partial & Ostrea edulis & 387598207 & 13.646 & 5.27 & 47 & $6 \%$ & 2 & $2.06^{\mathrm{b}}$ \\
\hline \multicolumn{10}{|l|}{ Others } \\
\hline 214 & Hypothetical protein CGI_10017570, partial & Crassostrea gigas & 405973072 & 72.905 & 5.16 & 49 & $1 \%$ & 1 & $2.12^{\mathrm{b}}$ \\
\hline
\end{tabular}

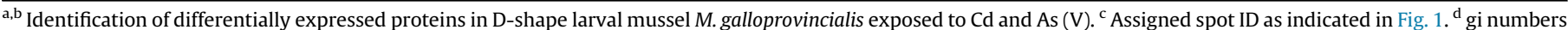

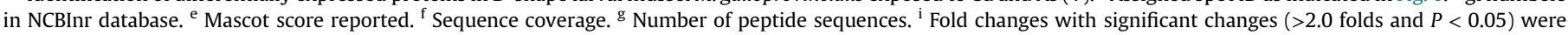
calculated using ImageMaster 2D Platinum 7.0. 
Inorganic pyrophosphatase catalyzes the reversible transfer of phosphoryl group from a polyphosphate to water and this reaction provides a thermodynamic pull for the synthesis of proteins and nucleic acids [33]. Deoxynucleoside 5'-monophosphate $\mathrm{N}$-glycosidase catalyzes the hydrolysis of the $\mathrm{N}$-glycosidic bond of the nucleotide to give deoxyribose 5-phosphate and a nucleobase, preferentially a purine [34]. The up-regulated inorganic pyrophosphatase and deoxynucleoside 5 '-monophosphate $\mathrm{N}$-glycosidase suggested the disturbance in nucleic acid metabolisms induced by $\mathrm{Cd}$ in D-shape larval mussels.

For As (V) treatment, only two identified proteins including Sadenosylhomocysteine hydrolase and ring box protein were significantly altered in D-shape larval mussels. It seemed that As (V) was less toxic than Cd to D-shape larval mussels. Due to its anion form $\left(\mathrm{AsO}_{4}^{3-}\right)$, As $(\mathrm{V})$ is much less permeable than other cations of metals to the marine animals. Therefore, As (V) might be less toxic than Cd to D-shape larval mussels. S-adenosylhomocysteine hydrolase is a cytosolic enzyme that has important functions in the cytosolic metabolism linking processes of transmethylation, transsulfuration, and purine metabolism [35]. In a previous study, Company et al. (2011) pointed out that S-adenosylhomocysteine hydrolase was related to oxidative stress conditions and might be affected by reactive oxygen species-inducing stressors, including metals [35]. Obviously, the altered S-adenosylhomocysteine hydrolase implied that As (V) induced oxidative stress via different pathways compared with $\mathrm{Cd}$ exposure in D-shape larval mussels. Ring box protein is essential for cell proliferation and embryonic development in organisms [36]. The up-regulated ring box protein suggested that As (V) influenced cell proliferation in D-shape larval mussels.

\subsection{Metabolomic responses in D-shape larval mussels exposed to Cd and As (V)}

Fig. 3 shows the representative ${ }^{1} \mathrm{H}$ NMR spectra of extracts from D-shape larval mussels from control, Cd and As (V) treatments. A total of 31 metabolites were identified in D-shape larval mussel samples, including amino acids (valine, leucine, isoleucine, alanine, threonine, glycine, etc.), osmolytes (betaine, homarine, dimethylglycine, taurine and hypotaurine), intermediates in the Krebs cycle (succinate and fumarate) and energy metabolism-related metabolites (glucose, glycogen and ATP).

The supervised pattern recognition method, OPLS-DA, was performed on the NMR spectral data for metabolic biomarker discovery in Cd- and As (V)-treated mussel groups, respectively (Fig. 4). The scores plots indicated the robust separation between control and treatments with reliable $\mathrm{Q}^{2}$ values ( $>0.6$ ) (Fig. $4 \mathrm{~A}$ and C). From the loading plot (Fig. 4B), the concentrations of alanine, glutamine, acetoacetate, succinate, hypotaurine and glycine were significantly $(P<0.05)$ decreased in Cd-treated D-shape larval mussel samples. However, the concentrations of aspartate and phosphocholine were significantly $(P<0.05)$ increased. Compared to the metabolic profile from Cd-treated group, several metabolites were similarly altered including alanine, acetoacetate, aspartate and phosphocholine in As (V)-treated group (Fig. 4D). However, elevated dimethylglycine and betaine and depleted $\beta$-alanine, malonate, glucose and glycogen were uniquely detected in As (V)treated mussel samples.

Hypotaurine is a known osmolyte in marine bivalves. The free amino acids are usually involved in two main pathways including oxidation for energy production and osmoregulation [10]. In the $\mathrm{Cd}$-treated group, the depleted hypotaurine, glutamine, glycine and alanine implied that $\mathrm{Cd}$ exposure disturbed osmotic regulation in D-shape larval mussels. In addition, alanine is also the major end product in the anaerobic breakdown of glucose in bivalves [37].

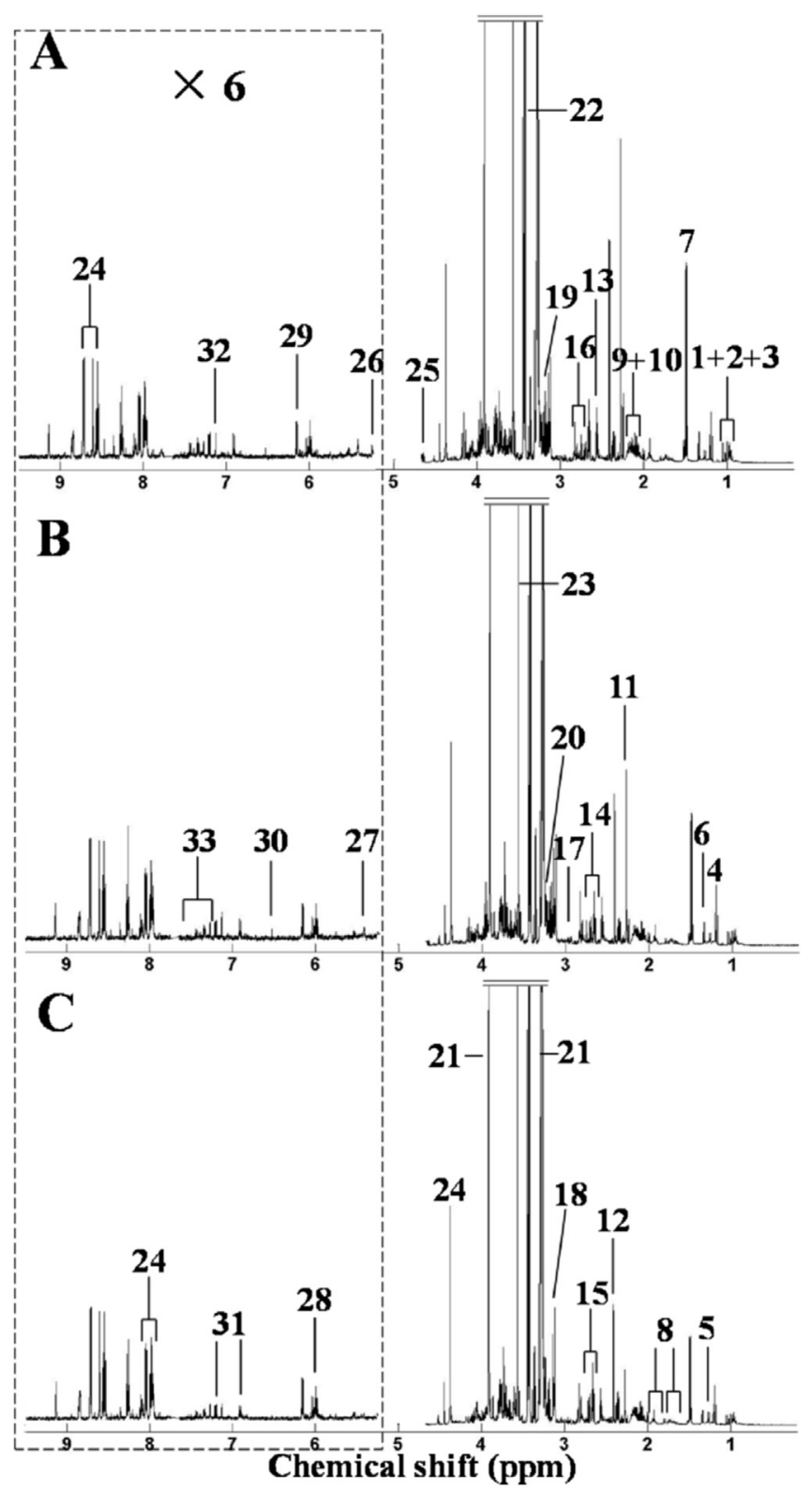

Fig. 3. Representative 1-dimensional ${ }^{1} \mathrm{HNMR}$ spectra of metabolite extracts from control (A), Cd- (B) and As (V)-treated (C) D-shape larval mussels M. galloprovincialis. Keys: (1) isoleucine, (2) leucine, (3) valine, (4) unknown 1 (1.20 ppm), (5) ethanol, (6) threonine, (7) alanine, (8) arginine, (9) glutamate, (10) glutamine, (11) acetoacetate, (12) succinate, (13) $\beta$-alanine, (14) hypotaurine, (15) aspartate, (16) asparagine, (17) dimethylglycine, (18) malonate, (19) choline, (20) phosphocholine, (21) betaine, (22) taurine, (23) glycine, (24) homarine, (25) $\beta$-glucose, (26) $\alpha$-glucose, (27) glycogen, (28) unknown 2 (5.98 ppm), (29) ATP, (30) fumarate, (31) tyrosine, (32) histidine and (33) phenylalanine.

Decreased alanine may be related to the reduced anaerobic metabolism induced by $\mathrm{Cd}$ in D-shape larval mussels. In one possible metabolic pathway, aspartate may be converted into succinate with no detectable changes in other compounds under anoxic conditions in mollusk resulting in the decreased aspartate and increased succinate [38]. Therefore the increased aspartate and decreased succinate meant the reduced anaerobic metabolism in Cd-treated D-shape larval mussels, which was consistent with the decreased alanine. Acetoacetate is a ketone body synthesized from acetylcoenzyme $A$ as the end product of fatty acid metabolism. The depleted acetoacetate implied the reduced lipid metabolism in D- 

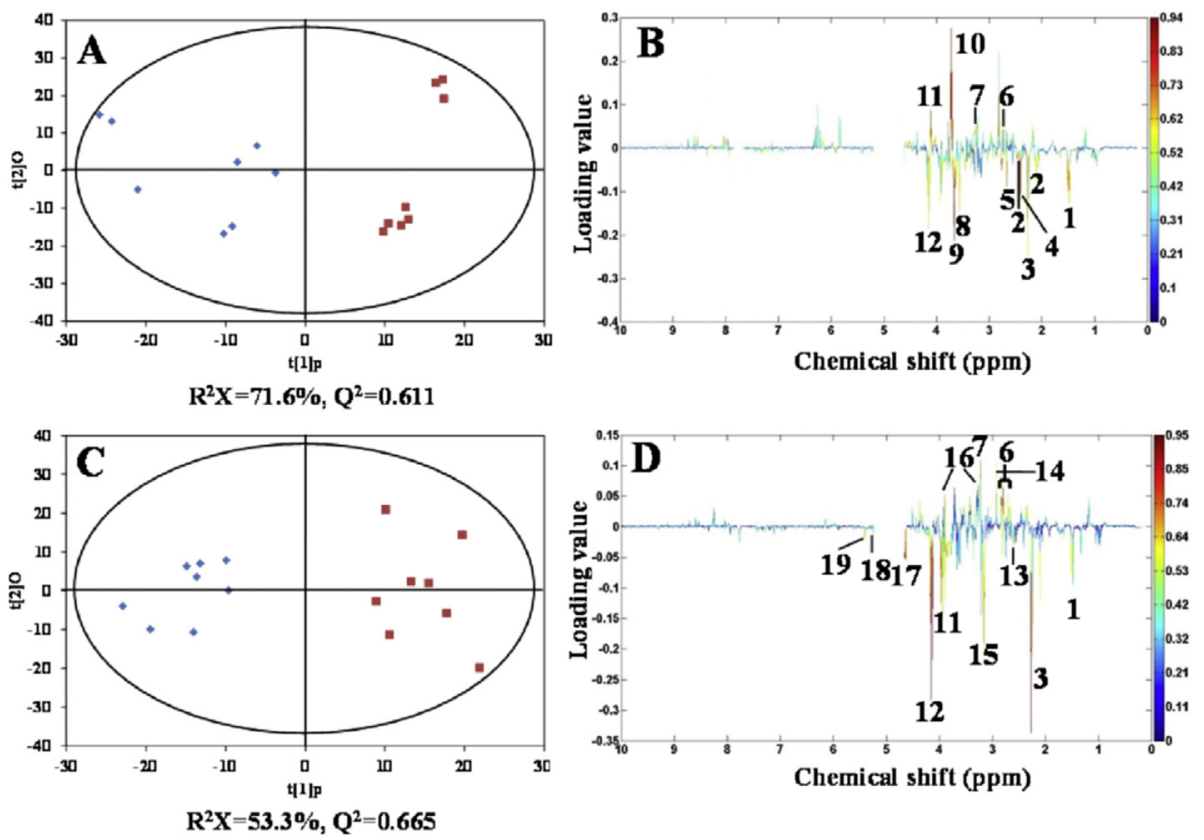

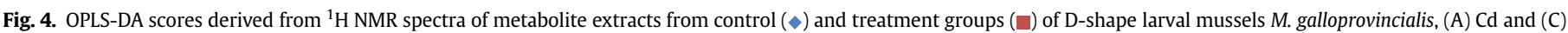

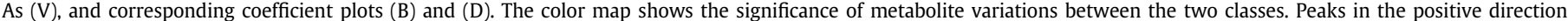

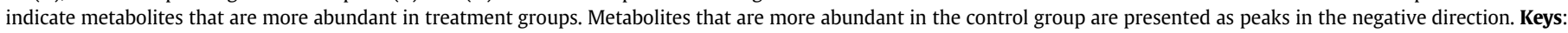

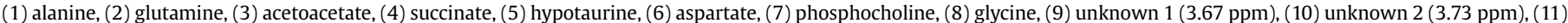
unknown 3 (3.95 ppm), (12) unknown 4 (4.15 ppm), (13) $\beta$-alanine, (14) dimethylglycine, (15) malonate, (16) betaine, (17) $\beta$-glucose and (18) $\alpha$-glucose and (19) glycogen.

shape larval mussels. Choline and ATP can be catalyzed into phosphocholine and ADP by choline kinase, which is related to energy metabolism. The elevated phosphocholine suggested that Cd exposure enhanced the conversion of choline to phosphocholine in D-shape larval mussels.

For the As (V) treatment, alanine, acetoacetate, aspartate and phosphocholine, were similarly altered in D-shape larval mussels. These metabolic responses exhibited that As (V) induced disturbances in energy metabolism and osmotic regulation and reduced lipid metabolism in D-shape larval mussels compared with those in Cd-treated group. Although aspartate was increased in As (V)treated samples, however, succinate was not significantly decreased, which suggested that the increased aspartate might be related to the disturbed osmotic regulation. The uniquely altered metabolites, including dimethylglycine, betaine, $\beta$-alanine, malonate, glucose and glycogen, indicated the differential biological effects of As (V) exposure, compared with those induced by $\mathrm{Cd}$ exposure in D-shape larval mussels. As two main osmolytes, dimethylglycine and betaine, were significantly elevated, indicating the obvious osmotic stress in D-shape larval mussels, together with the elevated amino acid, aspartate. Apparently, the altered dimethylglycine and betaine suggested that As (V) induced osmotic stress in D-shape larval mussels via different pathways compared with $\mathrm{Cd}$. The two depleted amino acids, alanine and $\beta$-alanine, might be used to compensate the elevated dimethylglycine and betaine involved in osmotic regulation. Malonate is a competitive inhibitor of the enzyme succinate dehydrogenase that is involved in the Krebs cycle. Therefore, the decreased malonate suggest that As (V) influenced energy metabolism, while decreased glucose and glycogen indicated the mobilization of energy reserves induced by As (V) exposure in D-shape larval mussels.

In summary, the biological effects of the environmentally relevant concentration of $\mathrm{Cd}$ and $\mathrm{As}(\mathrm{V})$ were characterized in the early life stage (D-shape larvae) of mussels M. galloprovincialis using a combined proteomic and metabolomic approach. Basically, proteomic responses indicated that $\mathrm{Cd}$ exposure induced obvious immune stress, oxidative stress, cellular injury and disturbance in nucleic acid metabolism in D-shape larval mussels. Interestingly, however, only two identified proteins were significantly altered in As (V)-treated group, which implied that D-shape larval mussel was less sensitive to As $(\mathrm{V})$ than to $\mathrm{Cd}$ at protein level. These two proteins in response to As (V) exposure suggested As (V) influenced anti-oxidative system and cell proliferation in D-shape larval mussels. The metabolic responses indicated that $\mathrm{Cd}$ and As (V) induced clear disturbances in osmotic regulation and energy metabolism in D-shape larval mussels via different metabolic pathways. In addition, $\mathrm{Cd}$ reduced the lipid metabolism in D-shape larval mussels. This work demonstrated that a combination of proteomics and metabolomics could provide an insightful view in the biological effects of pollutants in mussel M. galloprovincialis at early life stage.

\section{Acknowledgments}

This work was supported by NSFC (41676114) and Natural Science Foundation of Shandong Province (JQ201310). We thank Prof. Mark Viant (School of Bioscience, The University of Birmingham) for the use of ProMetab software.

\section{References}

[1] J. Mu, The Evaluation of Ecological Environment for Key Fishery Waters in Bohai Sea (In Chinese). Master's thesis, Ocean University of China, 2009.

[2] W. Liu, W. Qiu, J. Chen, Distribution characteristics of trace pollutants in benthic mussels from the coastal areas of Bohai Sea and north Yellow Sea (In Chinese), Environ. Sci. 32 (2011) 445-451.

[3] C. Ji, D. Yu, Q. Wang, F. Li, J. Zhao, H. Wu, Impact of metal pollution on shrimp Crangon affinis by NMR-based metabolomics, Mar. Pollut. Bull. 106 (2016) 372-376.

[4] R. Chester, Marine Geochemistry, Allen \& Unwin, Australia, 1990, p. 698.

[5] J.M. Neff, Ecotoxicology of arsenic in the marine environment, Environ. Toxicol. Chem. 16 (1997) 917-927. 
[6] K. Bouilly, B. Gagnaire, M. Bonnard, H. Thomas-Guyon, T. Renault, P. Miramand, S. Lapègue, Effects of cadmium on aneuploidy and hemocyte parameters in the Pacific oyster, Crassostrea gigas, Aquat. Toxicol. 7 (2006) 149-156.

[7] M. Chang, W. Wang, A. Wang, T.T. Tian, P. Wang, Y. Zheng, Y. Liu, Effects of cadmium on respiratory burst, intracellular $\mathrm{Ca}^{2+}$ and DNA damage in the white shrimp Litopenaeus vannamei, Comp. Biochem. Physiol. Part C 149 (2009) 581-586.

[8] R. Company, A. Serafim, M.J. Bebianno, R. Cosson, B. Shillito, A. Fiala-Médioni, Effect of cadmium, copper and mercury on antioxidant enzyme activities and lipid peroxidation on the gills of the hydrothermal vent mussel Bathymodiolus axoricus, Mar. Environ. Res. 58 (2004) 377-381.

[9] T.D. Williams, N. Turan, A.M. Diab, H. Wu, C. Mackenzie, K.L. Bartie, O. Hrydziuszko, B.P. Lyons, G.D. Stentiford, J.M. Herbert, J.K. Abraham, I. Katsiadaki, M.J. Leaver, J.B. Taggart, S.G. George, M.R. Viant, K.J. Chipman, F. Falciani, Towards a system level understanding of non-model organisms sampled from the environment: a network biology approach, PLoS. Comput. Biol. 7 (2011) 1-20.

[10] M.R. Viant, E.S. Rosenblum, R.S. Tjeerdema, NMR-based metabolomics: a powerful approach for characterizing the effects of environmental stressors on organism health, Environ. Sci. Technol. 37 (2003) 4982-4989.

[11] Q. Song, H. Chen, Y. Li, H. Zhou, Q. Han, X. Diao, Toxicological effects of benzo(a)pyrene, DDT and their mixture on the green mussel Perna viridis revealed by proteomic and metabolomic approaches, Chemosphere 144 (2016) 214-224.

[12] Q. Song, P. Zheng, L. Qiu, X. Jiang, H. Zhao, H. Zhou, Q. Han, X. Diao, Toxic effects of male Perna viridis gonad exposed to BaP, DDT and their mixture: a metabolomic and proteomic study of the underlying mechanism, Toxicol. Lett. 240 (2016) 185-195.

[13] E.D. Goldberg, M. Koide, V. Hodge, A.R. Flegal, J. Martin, U.S. Mussel Watch, 1977-1978 results on trace metals and radionuclides, Estuar. Coast. Shelf Sci. 16 (1983) 69-93.

[14] M.H. Salazar, S.M. Salazar, Tributyltin Effects on Juvenile Mussel Growth. OCEANS'87, IEEE, 1987, pp. 1504-1510.

[15] H. Wu, A.D. Southam, A. Hines, M.R. Viant, High-throughput tissue extraction protocol for NMR- and MS-based metabolomics, Anal. Biochem. 372 (2008) 204-212.

[16] P.A. Kirkland, J. Busby, S. Stevens Jr., J.A. Maupin-Furlow, Trizol-based method for sample preparation and isoelectric focusing of halophilic proteins, Anal. Biochem. 351 (2006) 254-259.

[17] F.W.-F. Lee, S.C.-L. Lo, The use of Trizol reagent (phenol/guanidine isothiocyanate) for producing high quality two-dimensional gel electrophoretograms (2-DE) of dinoflagellates, J. Microbiol. Meth. 73 (2008) 26-32.

[18] C. Ji, H. Wu, L. Wei, J. Zhao, J. Yu, Proteomic and metabolomic analysis reveal gender-specific responses of mussel Mytilus galloprovincialis to 2,2',4,4'-tetrabromodiphenyl ether (BDE 47), Aquat. Toxicol. 140-141 (2013) 449-457.

[19] E. Mortz, T.N. Krogh, H. Vorum, A. Gorg, Improved silver staining protocols for high sensitivity protein identification using matrix-assisted laser desorption/ ionization-time of flight analysis, Proteomics 1 (2001) 1359-1363.

[20] F. Gharahdaghi, C.R. Weinberg, D.A. Meagher, S.M. Mische, Mass spectrometric identification of proteins from silver-stained polyacrylamide gel: a method for the removal of silver ions to enhance sensitivity, Electrophoresis 20 (1999) 601-605.

[21] H. Katayama, T. Nagasu, Y. Oda, Improvement of in-gel digestion protocol for peptide mass fingerprinting by matrix-assisted laser desorption/ionization time-of-flight mass spectrometry, Rapid Commun. Mass Spectrom. 15 (2001) 1416-1421.

[22] A. Shevchenko, M. Wilm, O. Vorm, M. Mann, Mass spectrometric sequencing of proteins from silver-stained polyacrylamide gels, Anal. Chem. 68 (1996) $850-858$.

[23] Y. Gachet, S. Tournier, M. Lee, A. Lazaris-Karatzas, T. Poulton, U.A. Bommer, The growth-related, translationally controlled protein P23 has properties of atubulin binding protein and associates transiently with microtubules during the cell cycle, J. Cell Sci. 112 (1999) 1257-1271.

[24] J.L. Stark, K. Mehla, N. Chaika, T.B. Acton, R. Xiao, P.K. Singh, G.T. Montelione R. Powers, Structure and function of human DnaJ homologue subfamily a member 1 (DNAJA1) and its relationship to pancreatic cancer, Biochemistry 53 (2014) 1360-1372.

[25] S. Mkrtchian, M. Baryshev, O. Matvijenko, A. Sharipo, T. Sandalova, G. Schneider, M. Ingelman-Sundberg, Oligomerization properties of ERp29, an endoplasmic reticulum stress protein, FEBS Lett. 431 (1998) 322-326.

[26] W. Zhang, Q. Wei, Calcineurin stimulates the expression of inflammatory factors in RAW 264.7 cells by interacting with proteasome subunit alpha type 6, Biochem. Biophys. Res. Commun. 407 (2011) 668-673.

[27] N. He, H. Liu, X. Xu, Identification of genes involved in the response of haemocytes of Penaeus japonicus by suppression subtractive hybridization (SSH) following microbial challenge, Fish. Shellfish Immunol. 17 (2004) 121-128.

[28] H. Wu, C. Ji, L. Wei, J. Zhao, H. Lu, Proteomic and metabolomic responses in hepatopancreas of Mytilus galloprovincialis challenged by Micrococcus luteus and Vibrio anguillarum, J. Proteom. 94 (2013) 54-67.

[29] E.H. Sarsour, A.L. Kalen, P.C. Goswami, Manganese superoxide dismutase regulates a redox cycle within the cell cycle, Antioxid. Redox Signal 20 (2014) 1618-1627.

[30] E. Abele, E. Philip, P.M. Gonzalez, S. Puntarulo, Marine invertebrate mitochondria and oxidative stress, Front. Biosci. 12 (2007) 933-946.

[31] C. Ji, H. Wu, L. Wei, J. Zhao, iTRAQ-based quantitative proteomic analyses on the gender-specific responses in mussel Mytilus galloprovincialis to tetrabromobisphenol A, Aquat. Toxicol. 157 (2014) 30-40.

[32] N. Hirokawa, Kinesin and dynein superfamily proteins and the mechanism of organelle transport, Science 279 (1998) 519-526.

[33] A. Kornberg, On the metabolic significance of phosphorolytic and pyrophosphorolytic reactions, in: Horizons in Biochemistry, 1962, pp. 251-264.

[34] Y.K. Ghiorghi, K.I. Zeller, C.V. Dang, P.A. Kaminski, The c-Myc target gene Rcl (C6orf108) encodes a novel enzyme, deoxynucleoside 5'-monophosphate Nglycosidase, J. Biol. Chem. 282 (2007) 8150-8156.

[35] R. Company, O. Antúnez, M.J. Bebianno, M.P. Cajaraville, A. Torreblanca, 2-D difference gel electrophoresis approach to assess protein expression profiles in Bathymodiolus azoricus from Mid-Atlantic Ridge hydrothermal vents, J. Proteom. 74 (2011) 2909-2919.

[36] Y. Sasagawa, T. Urano, Y. Kohara, H. Takahashi, A. Higashitani, Caenorhabditis elegans RBX1 is essential for meiosis, mitotic chromosomal condensation and segregation, and cytokinesis, Genes Cells 8 (2003) 857-872.

[37] T.M. Stokes, J. Awapara, Alanine and succinate as end-products of glucose degradation in the clam Rangia cuneata, Comp. Biochem. Physiol. 25 (1968) 883-892.

[38] R.A. Graham, W.R. Ellington, Anaerobic aspartate metabolism and the formation of alanine in molluscan cardiac muscle: a ${ }^{13} \mathrm{C}$ NMR study, J. Exp. Zool. 236 (1985) 365-370. 